\title{
O Poema, o Prefácio e o Diálogo Necessário
}

\section{The poem, the preface and the necessary dialogue}

\author{
Wilton José Marques*
}

Vate! vate! que és tu?

(O vate, Gonçalves Dias)

A poesia verdadeira, a poesia completa está na harmonia dos contrários. (Prefácio a Cromwell, Victor Hugo)

O POETA E A TRADIÇÃO FUNDADA

O surgimento literário de Antônio Gonçalves Dias (1823-1864), que se deu com a publicação dos Primeiros cantos (1846), ${ }^{1}$ foi um acontecimento decisivo para a afirmação do movimento romântico no Brasil. Além de causar uma primeira sensação de mal-estar em relação à hegemonia literária de Gonçalves de Magalhães, o livro de estréia do poeta maranhense acabou por conferir ao Romantismo brasileiro um aspecto inovador, sobretudo ao dotar a poesia brasileira de uma originalidade própria tanto na

Universidade Federal de São Carlos - UFSCar

Apesar de ter a data de 1846, os Primeiros cantos só apareceram no mercado e foram distribuídos aos críticos, jornais e amigos do poeta no começo do ano seguinte, isto é, em janeiro de 1847. Em carta ao amigo Teófilo Leal, datada de 23 de janeiro de 1847, Gonçalves Dias escreve: "Os meus Primeiros cantos saíram à luz, têm me sido gabado em particular, o que de certo nada quer dizer; a gazeta oficial prometeu falar neles - assim como alguns outros, e até agora nada de novo". (DIAS, Gonçalves. Carta a Teófilo Leal, de 23 de janeiro de 1847. In: Correspondência ativa de Antônio Gonçalves Dias - Anais da Biblioteca Nacional. Rio de Janeiro, v. 84, 1964, p. 75). 
resolução do problema da nacionalidade literária quanto na expressão do sentimento romântico em si.

Assumindo, num espaço temporal relativamente curto, uma importância canônica, o primeiro livro de Gonçalves Dias, ao mesmo tempo em que fundava uma nova tradição poética, influenciou - quase que imediatamente - a formação da maioria dos poetas românticos, foi nele que as novas gerações literalmente aprenderam o Romantismo. Para o crítico Antonio Candido, a importância dos Primeiros cantos se deve notadamente ao fato de "o que antes era tema - saudade, melancolia, natureza, índio - se torna experiência, nova e fascinante, graças à superioridade da inspiração e dos recursos formais". ${ }^{2}$ Em tal leque de influência, para ficar em apenas dois exemplos românticos, cabia desde um "doce e meigo" Casimiro de $\mathrm{Abreu}^{3}$ até mesmo um "atormentado" Álvares de Azevedo. ${ }^{4}$

Além da influência sobre os seus contemporâneos, e denotando ainda uma força poética que obviamente ultrapassou os limites do próprio movimento romântico, a poesia de Gonçalves Dias também estabeleceu um diálogo constante e profícuo com quase todas as escolas literárias posteriores, chegando, inclusive, ao Modernismo. Tendo passado anteriormente pelas obras poéticas de Machado de Assis e de Olavo Bilac, ela ressoa de maneira bastante visível na obra de Carlos Drummond de Andrade. Antes de se decidir por Alguma poesia para título de seu livro de estréia, como efetivamente saiu em 1930, o poeta mineiro tinha dado a este seu primeiro volume de poemas o sugestivo nome de Minha terra tem palmeiras, como testemunha Mário de Andrade em carta não datada, provavelmente de meados dos anos 1920, ao próprio Drummond. O escritor paulista deixa claro

1981, p. 83.

CANDIDO, Antonio. Formação da literatura brasileira. 6. ed. Belo Horizonte: Itatiaia,

No prefácio de Primaveras (1859), Casimiro de Abreu assume de público a influência de Gonçalves Dias ao escrever que: "O filho dos trópicos deve escrever numa linguagem propriamente sua - lânguida como ele, quente como o sol que o abrasa, grande e misteriosa como as suas matas seculares; o beijo apaixonado das Celutas deve inspirar epopéias como as dos Timbiras - e acordar os Renés enfastiados do desalento que os mata. Até então, até seguirmos o vôo arrojado do poeta de Y-Juca Pirama [grifos meus], nós cantores novéis que se perdem no conjunto duma grande orquestra; há o único mérito de não ficarmos calados". (ABREU, Casimiro. Primaveras. In: Obras de Casimiro de Abreu. Rio de Janeiro: MEC, 1955, p. 45).

4 No discurso em comemoração ao aniversário dos cursos jurídicos no Brasil, em 11 de agosto de 1849, Álvares de Azevedo reconhece em Gonçalves Dias uma fonte de inspiração para os novos autores: "Perdoai-me, Senhores, se calei-vos as emoções que me desperta o dia das grandes reminiscências, a verdadeira era da nossa Nacionalidade. Perdoai se achei mais digno de vós recordar-vos o brilhantismo do passado e as esperanças do porvir - lembrar-vos a grandeza de vossa missão civilizadora.

Bem haja àqueles de vós que tão bem a compreendem, a esses que aí por nossa terra vão acordando o amor literário, a essa mocidade que seguindo o impulso de um livro fadado a fazer época em nossa história literária, porque foi um livro criador - os Primeiros cantos, do Sr. Gonçalves Dias - que veio regenerar-nos a rica poesia nacional de Basílio da Gama e Durão". [grifos meus] (AZEVEDo, Álvares. Discurso. In: Obras completas de Álvares de Azevedo. Rio de Janeiro: Nacional, v. 2, 1942, p. 399-415). 
uma ponta de inveja pela escolha do nome do livro: "No Minha terra tem palmeiras - escreve Mário -, nome admirabilíssimo que eu invejo, há poemas excelentes e muita coisa boa". ${ }^{5}$

O POETA E A TEORIA

De qualquer modo, e mesmo a despeito de sua posterior influência na literatura brasileira, Gonçalves Dias, como resultado de seu processo de formação estética, dialogou intensamente com a tradição literária ocidental, e, nesse sentido, soube contemplar já nos Primeiros cantos, apesar dos altos e baixos inerentes a todo livro de estréia, alguns dos principais temas norteadores do imaginário romântico, e, entre eles, a própria definição do conceito de poesia. De maneira geral, pode-se dizer que a consciência do poeta em relação ao alcance, ou até mesmo aos possíveis limites, de seu labor artístico transforma-se em questão fundante para a literatura, e respondê-la é condição necessária para o entendimento de sua poética.

Se se pensar no caso extremo de João Cabral de Melo Neto, para ficar aqui num exemplo emblemático, tal consciência de composição, levada racionalmente até as últimas conseqüências, torna-se matéria poética de recorrente pensar. Já no caso de Gonçalves Dias, um romântico por inteiro, o problema poético estrutura-se de outro modo, pois a poesia romântica, antes de voltar-se para si como tema, quer na verdade interferir na teia de relações histórico-estéticas que rege a sociedade humana. Ou, em outras palavras, a poesia romântica, ancorando-se na subjetividade como princípio de tudo, procura, num esforço de entendimento da natureza do próprio poético, conjugar em si a harmonia e o caos dessa mesma sociedade.

De imediato, já no pequeno prólogo que abre seus Primeiros cantos, Gonçalves Dias traduz a sua concepção de poesia, desejando entendê-la como lugar privilegiado de conciliação dos contrários:

Com a vida isolada que vivo, - escreve o poeta - gosto de afastar os olhos de sobre a nossa arena política para ler em minha alma, reduzindo à linguagem harmoniosa e cadente o pensamento que me vem de improviso, e as idéias que em mim desperta a vista de uma paisagem ou do oceano - o aspecto enfim da natureza. Casar assim o pensamento com o sentimento - o coração com o entendimento - a idéia com a paixão - colorir tudo isto com a imaginação, fundir tudo isto com a vida e com a natureza, purificar tudo com o 
sentimento da religião e da divindade, eis a Poesia - a Poesia grande e santa - a Poesia como eu a compreendo sem a poder definir, como eu a sinto sem a poder traduzir. ${ }^{6}$

Se, por um lado, a definição "indefinida" de Gonçalves Dias atesta de antemão a crença romântica na incapacidade de expressão plena da linguagem - "sinto sem a poder traduzir" - diante das várias possibilidades temáticas decorrentes da relação entre o poeta e a natureza; por outro, tal definição passa pelos vários lugares comuns da estética romântica. Partindo da solidão, condição necessária para o primado do "eu", o poeta entende-se como o intérprete das suas próprias impressões, uma vez que quer reduzir à linguagem harmoniosa tanto o pensamento que lhe vem de improviso quanto as idéias que nele são despertadas pela natureza. Como observa o crítico Luiz Roncari, Gonçalves Dias, na verdade, concentra em si a dupla capacidade de "sentir o que está fora dele e a de expressar o que se passa internamente", possibilitando ao leitor vislumbrar "os sentimentos interiores e subjetivos do poeta acerca do mundo, da natureza e da divindade". ${ }^{7}$

Desse modo, é possível constatar que a poética de Gonçalves Dias, em perfeita consonância com os principais paradigmas estéticos do Romantismo, é um bom exemplo corroborativo do deslocamento de objetividade que permeia a poesia romântica. Ao contrário do pensamento clássico que, como se sabe, apresenta uma visão da natureza e do homem balizadas pela mimesis aristotélica, o pensamento romântico procura ancorar a sua preocupação artística somente na subjetividade. Guiado sempre por esta última, Gonçalves Dias tem claro para si a importância de se preservar a todo custo a sua individualidade criativa para poder expressar livremente seus sentimentos a respeito das coisas do mundo e da natureza, não sem antes, é claro, perpassar esses mesmos sentimentos, como ele mesmo afirma, pelo caráter purificador da religiosidade cristã.

\section{O POEMA}

Além de teorizar, no prólogo do livro de estréia, sobre a concepção poética que norteia o seu Romantismo, Gonçalves Dias se ocupou desse problema de maneira prática, isto é, por meio da própria poesia. Prova v. 1,1944, p. $17-18$

DIAS, Gonçalves. Obras poéticas de Antônio Gonçalves Dias. São Paulo: Nacional,

RONCARI, Luiz. Literatura brasileira: dos primeiros cronistas aos últimos românticos. São Paulo: Editora da Universidade de São Paulo, 1995, p. 306. 
disso foi a inclusão ainda nos Primeiros cantos do poema "O vate". Como o nome já sugere, o poeta, como todo artista que, para entender as razões de seu labor, sente necessidade de primeiro entender os liames da própria arte, apresenta a "sua visão" sobre o papel que deve desempenhar o autor romântico em contraposição aos que o precederam. Pela análise e interpretação desse texto, procurar-se-á aqui explicitar melhor o olhar gonçalvino sobre sua poética.

Escrito ainda em Coimbra, onde estudara Direito, e dedicado ao poeta medievista e dramaturgo português José Freire de Serpa Pimentel,,$^{8} \mathrm{o}$ poema de Gonçalves Dias se articula em torno da historicização do processo evolutivo da poesia até o Romantismo. Precedido, na forma de epígrafe, por versos de Victor Hugo, ${ }^{9}$ o texto, do ponto de vista temático, estrutura-se em função da questão crucial que já vem expressa no primeiro verso: "Vate! vate! que és tu?". Entendê-la é, acima de tudo, entender a visão do próprio poeta em relação ao seu papel de romântico, e por conseqüência de sua poesia, frente à tradição cultural herdada. Veja-se o texto:

Vate! vate! que és tu? — Nos seus extremos

Fadou-te Deus um coração de amores,

Fadou-te uma alma acesa borbulhando

Ardidos pensamentos, como a lava

Que o gigante Vesúvio arroja às nuvens.

Vate! vate! que és tu? - Foste ao princípio

Sacerdote e profeta;

Eram nos céus teus cantos uma prece,

$\mathrm{Na}$ terra um vaticínio.

E ele cantava então: - Jeová me disse,

Majestoso e terrível.

8 José Freire de Serpa Pimentel (1814-1870) - Contemporâneo de Gonçalves Dias na Universidade de Coimbra, Serpa Pimentel foi um dos principais colaboradores da revista Crônica literária da Nova Academia Dramática (1840-1841). Apesar de ser uma revista dedicada notadamente ao teatro, saíram na Crónica, no campo da literatura não dramática, vários contos, baladas, xácaras sobre lendas ou fatos históricos da história portuguesa na Idade Média. Essa publicação, em que os versos de Serpa Pimentel se destacavam, foi uma das fontes em que Gonçalves Dias bebeu o medievismo coimbrão que ressoou diretamente na elaboração de seu projeto indianista.

9 Os versos de Victor Hugo, traduzidos aqui por Manuel Bandeira, procuram louvar os esforços e os triunfos dos poetas:

"Eu... eu amaria tua vitória;

Para meu coração, amante de toda glória,

Os triunfos dos outros não são uma afronta.

Poeta, eu tinha sempre uma canção para os poetas,

E jamais o louro que enfeita outras cabeças

Joga sombra sobre minha fronte".

(HUGO, Victor. Moi... j'aimerai ta victoire. In: Gonçalves Dias. 14. ed. Rio de Janeiro: Agir, 1996, p. 47). 
"Vês tu Jerusalém como orgulhosa

Campeia entre as nações, como no Líbano

Um cedro a cuja sombra a hissope cresce?

Breve a minha ira transformada em raios

Sobre ela cairá;

Um fero vencedor dentro em seus muros

Tributária a fará;

E quando escravos seus filhos, sobre pedra

Pedra não ficará”.

E os réprobos de saco se vestiam,

Em pó, em cinza envoltos;

E colando co'a terra os torpes lábios

E açoitando co'as mãos o peito imbele, Senhor! Senhor! - clamavam.

E o vate entanto o pálido semblante

Meditabundo sobre as mãos firmava,

Suplicando ao Senhor do interno d'alma.

Foram santos então. - Homero o mundo

Criou segunda vez, - o inferno o Dante, -

Milton o paraíso, - foram grandes!

E hoje!... em nosso exílio erramos tristes,

Mimosa esp'rança ao infeliz legando,

Maldizendo a soberba, o crime, os vícios;

E o infeliz se consola, e o grande treme.

Damos ao infante aqui do pão que temos,

E o manto além ao mísero raquítico;

Somos hoje Cristãos. ${ }^{10}$

Como já se disse, o ponto de partida do poema de Gonçalves Dias é a questão crucial expressa no primeiro verso: "Vate! vate! que és tu?". A resposta, no entanto, não se apresenta de maneira imediata, pois, para se chegar a ela, é preciso, antes de mais nada, reconhecer a existência no corpo do texto de quatro momentos distintos que, compostos por uma irregular divisão estrófica, varrem a tradição poética até o Romantismo. Desse modo, cada momento, como se fosse um pequeno tijolo, compõe a arquitetura da resposta ansiada, e, sumariamente, pode ser assim reconhecido: o primeiro, que se reduz à estrofe inicial, introduz a questão crucial e detecta características inerentes ao poeta, inclusive, ao romântico; o segundo, com- 
preendido pelas três seguintes estrofes, apresenta o poeta como sacerdote e profeta; o terceiro, reduzido à quinta estrofe, estabelece um diálogo entre o poeta e a tradição literária ocidental; e, por fim, o quarto momento, expresso pela sexta e última estrofe, define o papel que o poeta romântico deve desempenhar.

Se se atentar mais minuciosamente aos quatro momentos, é possível ver que, inicialmente, o poeta romântico, como traço distintivo em relação aos outros homens, reconhece-se como portador de características especiais - "um coração de amores" e "uma alma acesa borbulhando / Ardidos pensamentos" - que a ele são fadadas por Deus. A consciência de tais características confere uma dimensão especial à poesia, isto é, ela passa a ser em si, intermediada pela capacidade de sentir do poeta, a própria expressão da força da vontade divina. Tal descomunal vontade, que brota dos "ardidos pensamentos" concedidos ao poeta por Deus, é potencializada no poema pela imagem comparativa com a força, igualmente descomunal, das lavas do Vesúvio, isto é, da própria Natureza em ação.

No segundo momento do texto, o poeta, agora porta-voz dos desígnios de Deus, assume-se como sacerdote e, sobretudo, como profeta. Em sua essência, o profeta "designa o homem que fala ou o homem que é chamado, isto é, a quem foi dirigida uma palavra. Com efeito, a palavra é o meio de ação mais importante dos profetas; (...) é pela palavra que [eles] são verdadeiramente profetas". ${ }^{11}$ Assim a exemplo dos profetas, os poetas românticos também se expressam pela palavra revelada. Para corroborar essa verdade, Gonçalves Dias, em seu poema, apóia-se no testemunho do profeta Jeremias. A escolha de Jeremias não foi ao acaso, pois esse homem escolhido - "A palavra do senhor veio a mim: Vai bradar aos ouvidos de Jerusalém" - ${ }^{12}$ assim como o romântico o será, é não somente um grande solitário da palavra como também é um deslocado social, tanto que para definir sua relação com a sociedade, o profeta afirma: "Eu fico à margem". ${ }^{13}$ A marginalização, no entanto, não o impede de cumprir o seu destino, isto é, o de vaticinar que a ira divina se abaterá sobre Jerusalém por ela ter se afastado dos princípios de Deus: "Breve a minha ira transformada em raios / Sobre ela cairá", portanto, aos ouvidos surdos, restam apenas os pedidos de clamor.

Após recuperar a relação com Deus, o vate romântico, no terceiro momento do poema e ensimesmado no "interior d'alma", recorre novamente a Deus para encontrar na tradição ocidental que o precede os poetas que,

Loyola, 1994, p. 319

"Introdução aos livros proféticos". In: Bíblia (tradução ecumênica). São Paulo:

Bíblia, op. cit., p. 715 .

Bíblia, op. cit., p. 741 . 
vistos por ele com os olhos da santificação, são reconhecidos como modelares. Desse modo, o romântico vê em Homero, Dante e Milton, respectivamente os criadores do mundo, do inferno e do paraíso. O diálogo, e o conseqüente compromisso, com a tradição aparece em Gonçalves Dias como substrato universalizante de sua própria poesia. ${ }^{14}$

Por fim, no quarto momento, depois de historiada a tradição, a questão crucial é retomada em torno do papel que o poeta romântico - "E hoje!" - deveria necessariamente desempenhar. A resposta de Gonçalves Dias, retomando de certa maneira a marginalização do profeta Jeremias, é condicionada tanto pela consciência da solidão quanto pela consciência de seu "não-lugar" na sociedade. No entanto, mesmo sabendo-se um exilado errante, o poeta deve pautar sua lira pela compaixão cristã, legando esperança e consolando o infeliz, maldizendo "a soberba, o crime e os vícios", enfim, fazendo tremer "o grande" e praticando a caridade aos pobres, já que, em última instância, ele se reconhece, acima de tudo, como cristão.

\section{O DIÁLOGO PROGRAMÁTICO}

Nesse primeiro passar de olhos sobre "O vate", - e a despeito ainda do fato de que o texto em si apresenta um tom pesado se comparado com a melhor lírica gonçalvina e que talvez seja decorrente do caráter programático que o permeia -, é possível perceber que o mesmo se torna exemplo emblemático da primordial recuperação, feita pelo Romantismo, da crença de que a "verdade revelada" pela boca do profeta/poeta, ou, se quiser, captada pela sensibilidade do gênio, confere à subjetividade da poesia romântica um papel essencial para a conciliação do homem com o próprio Deus e, por conseqüência, do homem consigo mesmo. No entanto, se o poema gonçalvino for percorrido com mais vagar, pode-se detectar, subjacente ao pró-

14 A relação de Gonçalves Dias com a literatura ocidental foi extremamente frutífera e poderia ser exemplificada com o elevado número de autores que aparecem nas epígrafes com que abre grande parte de seus poemas. O crítico alemão Fritz Ackermann, estudando a obra do poeta, lista os seguintes autores: Ésquilo, Ovídio, Horácio, de quem traduziu várias odes, Virgílio, Dante, Petrarca, Tasso, Santo Agostinho, Metastassio, Cesarotti, Foscolo, Shakespeare, Byron, Zorrilla, Heredia, Goethe, Schiller, de quem traduziu uma peça de teatro - A Noiva de Messina -, Kleist, Wieland, Grabbe e Bürger, Chateaubriand, autor da epígrafe que abre as "Poesias Americanas" nos Primeiros cantos, Lamartine, Vigny, Musset, Victor Hugo, de quem traduziu a "Canção de BugJargal", e Saint-Beuve. Há também a influência dos românticos portugueses, sobretudo Alexandre Herculano, Almeida Garrett, Antônio Feliciano de Castilho.

Cf. ACKERMANN, Fritz. A obra poética de Antônio Gonçalves Dias. São Paulo: Conselho Estadual da Cultura, 1964. 
prio texto, a existência de um diálogo direto com a teoria poética desenvolvida por Victor Hugo no "Prefácio a Cromwell".

Ciente de seu papel histórico para com o Romantismo brasileiro, Gonçalves Dias dá vida ao caráter de missão que norteia sua literatura, dotando, inclusive, sua poesia de uma visão universal. Tal visão, legitimando o drama de se saber incompreendido e "sem lugar" no mundo e ainda explicitando uma influência que vai muito além da epígrafe, é construída pelo poeta maranhense por meio da correspondência entre os quatro momentos já identificados em "O vate" e a teoria das três idades poéticas estabelecida por Hugo no seu famoso prefácio. A seu modo, nesse sentido, o poema de Gonçalves Dias pode ser aqui entendido como uma (re)leitura do "Prefácio a Cromwell".

Em linhas gerais, o "Prefácio a Cromwell", em contraposição ao ideário clássico, é uma defesa ardorosa da poética romântica centrada, entre outros aspectos, na mistura dos gêneros, na rejeição das regras e, sobretudo, na completa liberdade da arte. Inicialmente, o escritor francês procura analisar o desenvolvimento da literatura ao longo da história com o intuito de fundamentar a caracterização da poesia moderna, isto é, a poesia romântica. Para Hugo, a poesia se sobrepõe sempre à sociedade, por isso, ele tenta desvendar qual deve ter sido o caráter da primeira nas três grandes idades do mundo: nos tempos primitivos, nos tempos antigos, nos tempos modernos.

o primeiro momento, o "tempo primitivo", é marcado pela inexistência de uma organização social mais complexa, assim, o maior objeto temático da poesia, como reflexo dessa pouca organização, é a representação da intensa relação entre Deus e o homem que acaba de nascer:

[O homem] - escreve Hugo - toca ainda de tão perto a Deus que todas as suas meditações são êxtases, todos os seus sonhos visões, (...) Sua lira tem somente três cordas: Deus, a alma, a criação; mas este triplo mistério envolve tudo, mas esta tripla idéia compreende tudo. ${ }^{15}$

Esse primeiro momento, em que, para o romântico francês, "a prece é toda sua religião: a ode é toda a sua poesia", ${ }^{16}$ é exemplificado por Gonçalves Dias em seu poema pela figura simbólica do profeta Jeremias "Eram nos céus teus cantos uma prece" -, pois o sentido primeiro do texto poético está, sobretudo, na relação direta com Deus.

15 HUGO, Victor. Do grotesco e do sublime (Tradução do "Prefácio a Cromwell"). São Paulo: Perspectiva, 1988, p. 16.

16 Ibid., p. 17. 
Já no segundo momento, o "tempo antigo", tanto o sacerdote quanto o rei passam a dividir entre si a "paternidade do povo". Assim, para Hugo, com a organização das nações ocorrem os conflitos inevitáveis, as migrações e as viagens, e a poesia então passa a refletir "estes grandes acontecimentos", passando agora das idéias para as coisas. "[A poesia] (...) canta os séculos, os povos, os impérios. Torna-se épica, gera Homero". Inevitavelmente, todos os poetas acabam indo "buscar inspiração no rio homérico. É sempre a Ilíada e a Odisséia". ${ }^{17}$ Essa dívida para com Homero também é resgatada por Gonçalves Dias que, em seu texto, afirma: "Homero o mundo / Criou segunda vez".

O terceiro momento, o "tempo moderno", é moldado pelo advento do cristianismo, a "religião completa", pois, este "ensina ao homem que ele tem duas vidas que deve viver, uma passageira, a outra imortal; uma da terra, outra do céu". ${ }^{18}$ Para Hugo, ao contrário da mimesis aristotélica, a principal característica da poesia moderna, notadamente a romântica, devese ao fato de o cristianismo conduzi-la à verdade, já que somente ele permite que a musa moderna veja "as coisas com um olhar mais elevado e mais amplo" e, portanto, percebendo que "tudo na criação não é humanamente belo, que o feio existe ao lado do belo, o disforme perto do gracioso, o grotesco no reverso do sublime, o mal com o bem, a sombra com a luz", ${ }^{19}$ ou seja, foi a religião cristã que permitiu ao poeta enxergar a diversidade das coisas, já que "o meio de ser harmonioso é ser incompleto".$^{20} \mathrm{~A}$ arte que melhor representa esse momento é o drama, que, para Hugo, nasce com Shakespeare. Ao fundir o grotesco e o sublime, o terrível e o bufo, a tragédia e a comédia, o dramaturgo inglês deu vida própria ao drama, que, conduzido agora pelos românticos, pretende reduzir os dois gêneros clássicos, a tragédia e a comédia, a um só, opondo, como afirma o crítico Décio de Almeida Prado, "dentro do mesmo contexto o riso à lágrima, não só à maneira de Shakespeare mas de acordo com o dualismo cristão - corpo e alma, terra e céu, homem e Deus -, inspirador, segundo o 'Prefácio', de toda arte moderna”. ${ }^{21}$

Além do bardo inglês, o romântico francês cita como exemplos máximos da nova poesia Dante e Milton: "os dois únicos poetas dos tempos modernos que são do porte de Shakespeare" e que "concorrem com ele para imprimir a tinta dramática em toda a nossa poesia". ${ }^{22}$ Sintomaticamente e corroborando essa visão de Victor Hugo, Gonçalves Dias, em "O vate", tam-

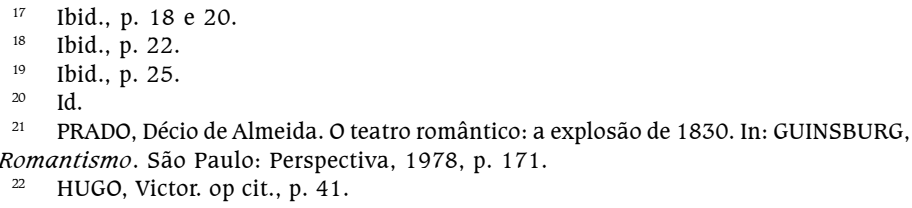


bém faz menção a esses dois poetas: "—o inferno o Dante, - / Milton o paraíso, - foram grandes!".

Por fim, depois de caracterizar o tempo primitivo como lírico, a antigo como épico e o moderno como dramático, a profissão de fé de Victor Hugo encerra-se pela reafirmação da superioridade da poesia moderna calcada no cristianismo:

...a poesia nascida do cristianismo, a poesia de nosso tempo é, pois, o drama; o caráter do drama é o real; o real resulta da combinação bem natural de dois tipos, o sublime e o grotesco, que se cruzam no drama, como se cruzam na vida e na criação. Porque a verdadeira poesia, a poesia completa, está na harmonia dos contrários. Depois, é tempo de dizê-lo em voz alta, e é aqui sobretudo que as exceções confirmariam a regra, tudo o que está na natureza está na arte. ${ }^{23}$

A adesão de Gonçalves Dias a essa tese é tão completa que, ao concluir seu poema com o verso: "Somos hoje Cristãos", ${ }^{24}$ ele se reconhece como herdeiro e se insere como poeta nessa nova tradição. Portador desse substrato religioso, o poeta maranhense, a seu modo, inclui-se nessa modernidade romântica, pois, somente assim, assumindo sua condição de gênio, isto é, de mediador entre o Eu e a Natureza exterior ${ }^{25}$ e, portanto, "o único que pode fazer inclinar a balança da arte", ${ }^{26}$ ele pôde, casando "o pensamento com o sentimento", como registrou no prólogo de seu livro, perceber não somente que a poesia "está na harmonia dos contrários", mas também que "tudo o que está na natureza está na arte".

23 Ibid., p. 42.

24 A adesão gonçalvina à tradição da poesia moderna pode ainda ser ainda reforçada se se levar em consideração que, na primeira edição dos Primeiros cantos, os versos 29 e 31 eram respectivamente "Fomos santos então. - Homero o mundo" e "Milton o paraíso - fomos grandes!". (Apud. BANDEIRA, Manuel. In: Obras poéticas de Antônio Gonçalves Dias. op. cit., p. 125).

${ }_{25}$ No artigo "A visão romântica”, o crítico Benedito Nunes define o lugar do gênio na sociedade, caracterizando-o, sobretudo, como o mediador entre o Eu e a Natureza: "Mas o poeta é o gênio por excelência; mediador entre o Eu e a Natureza exterior, o gênio nacional floresce através e por força de suas obras, a cuja linguagem se vai conferir um alcance original formativo, à altura do trabalho do legislador e próximo do visionarismo místico e profético, quando não de uma importância transcendente à especulação do filósofo, à atividade política e à ciência, que ele possibilita, elucida e perpetua. É que, altivo, incompreendido e distante, o poeta romântico impõese, intimado pela inspiração que o visita, a atarefa universal de legislador do reino dos fins espirituais intangíveis, onde, inume à lei da causalidade e às mutáveis circunstâncias do mundo exterior, ocupa, como o viu Lamartine, um lugar firme e elevado em relação à humanidade". (NUNES, Benedito. A visão romântica. In: GUINSBURG J. (Org.). O Romantismo. São Paulo: Perspectiva, 1978, p. 62).

26 HUGO, Victor. op cit., p. 71. 
A CONSCIÊNCIA DO VATE

Em suma, pode-se ler "O vate" como um diálogo programático com o "Prefácio a Cromwell", ou ainda, se quiser, como um "poema de intenções", em que aparecem preocupações temáticas que empurram a poética gonçalvina para além do redutor viés nacionalista que a crítica literária comumente a interpreta. Essa relação com a tradição européia ocidental, exemplificada aqui pelo diálogo com Victor Hugo, é um traço constante no projeto poético gonçalvino, uma vez que ele é construído não somente pelo mergulho nos problemas e angústias tanto da expressão literária brasileira, que se queria nacional, quanto da própria história local, que se queria legitimadora, mas também pelo mergulho no estudo dos problemas e angústias da expressão literária européia. Dessa forma, denotando superioridade em relação aos seus pares românticos, a poesia de Gonçalves Dias afirma-se, de um lado, na perfeita harmonia da medida, herança da influência neoclássica, e do vigor romântico propriamente dito; e, de outro, na relação dialética, inerente à formação de culturas periféricas, de amalgamar valores estéticos originários de duas realidades culturais distintas: uma solidificada, a européia; e outra ainda construindo-se, a brasileira.

A seu modo, Gonçalves Dias integrou dialeticamente às cores locais de sua poesia o influxo externo, e com isso, relendo tanto a tradição brasileira como também a européia, criou um projeto poético que, por si só, instaurou uma nova tradição na poesia brasileira. Nesse sentido, a poesia de Gonçalves Dias poderia muito bem ser usada para exemplificar a resposta que o escritor argentino, Jorge Luis Borges, propõe ao teorizar sobre qual deveria ser a postura do escritor argentino frente à tradição européia. Para Borges, a tradição a que o escritor argentino e os escritores latino-americanos em geral, por estarem em situação análoga, deveriam estar sujeitos é toda a cultura ocidental: "podemos lançar mão de todos os temas europeus, utilizá-los sem superstições, com uma irreverência que pode ter, e já tem, conseqüências afortunadas". ${ }^{27}$ De certo modo, para a literatura brasileira, $o$ aparecimento dos Primeiros cantos pode sintomaticamente ser visto como uma dessas conseqüências. 


\title{
RESUMO
}

O artigo faz uma leitura do poema "O vate", de Gonçalves Dias. Essa leitura intenta mostrar a existência de um diálogo entre o poema e a teoria poética desenvolvida por Victor Hugo no "Prefácio a Cromwell". Tal diálogo explicita a consciência do poeta em relação ao seu papel no Romantismo brasileiro e, ao mesmo tempo, confere um traço universal à sua obra poética.

Palavras-chave: Literatura romântica; Gonçalves Dias; Victor Hugo.

\begin{abstract}
This article presents a reading of the poem "O vate" (The poet) written by Gonçalves Dias. The aim is to show the existence of a dialogue between that poem and the poetic theory developed by Victor Hugo in "Preface to Cromwell". Such dialogue makes explicit the poet's conscience of his role in Brazilian Romanticism and, at the same time, gives a universal dimension to his poetic work.
\end{abstract}

Key-words: Romantic literature; Gonçalves Dias; Victor Hugo.

\section{REFERÊNCIAS}

ABREU, Casimiro. Obras de Casimiro de Abreu. Rio de Janeiro: MEC, 1955.

ACKERMANN, Fritz. A obra poética de Antônio Gonçalves Dias. São Paulo: Conselho Estadual da Cultura, 1964.

ANDRADE, Carlos Drummond. A lição do amigo - cartas de Mário de Andrade a Carlos Drummond de Andrade. 2. ed. Rio de Janeiro: Record, 1988.

AZEVEDO, Álvares. Obras completas de Álvares de Azevedo. Rio de Janeiro: Nacional, v. 2, 1942.

BÍBLIA. São Paulo: Loyola, 1994. (tradução ecumênica).

BORGES, Jorge Luis. Obras completas de Jorge Luis Borges. São Paulo: Globo, v.1, 1998.

CANDIDO, Antonio. Formação da literatura brasileira. 6. ed. Belo Horizonte: Itatiaia, 1981.

DIAS, Gonçalves. Obras poéticas de Antônio Gonçalves Dias. São Paulo: Nacional, v. 1, 1944.

. Gonçalves Dias. 14. ed. Rio de Janeiro: Agir, 1996.

. Correspondência ativa de Antônio Gonçalves Dias - Anais da Biblioteca Nacional.

Rio de Janeiro, v. 84, 1964. 
MARQUES, W. J. O poema, o prefácio e o diálogo necessário

GUINSBURG, J.(Org.). O Romantismo. São Paulo: Perspectiva, 1978.

HUGO, Victor. Do grotesco e do sublime. São Paulo: Perspectiva, 1988.

RONCARI, Luiz. Literatura brasileira: dos primeiros cronistas aos últimos românticos. São Paulo: Editora da Universidade de São Paulo, 1995. 